\title{
A New Mutation in Diagnosis of Wolman Disease: Case Report
}

\author{
Mehmet Şerif Cansever ${ }^{1}$ (D), Mine Aslan³ (D), Tanyel Zübarioğlu² (1) \\ ${ }^{1}$ Medical Laboratory Techniques, Namık Kemal University, Vocational Health High School, Tekirdağ, Turkey \\ 2Department of Pediatrics, Clinic of Child Metabolism, University of Health Sciences Şişli Hamidiye Etfal Training and Research Hospital, İstanbul, \\ Turkey \\ ${ }^{3}$ Department of Radiology, İstanbul University Cerrahpaşa School of Medicine, İstanbul, Turkey
}

Cite this article as: Cansever MŞ, Aslan M, Zübarioğlu T. A New Mutation in Diagnosis of Wolman Disease: Case Report. JAREM $2019 ;$ 9(3): 150-2.

\begin{abstract}
Wolman disease (WD) is caused by the complete loss of lysosomal acid lipase (LAL) activity that is essential for hydrolysis of cholesterol esters and triglycerides. It presents with vomiting, diarrhea, poor weight gain, and hepatomegaly subsequently leading to death in infancy. Definite diagnosis is based on genetic confirmation by the LIPA gene sequencing. Several types of mutations, including point mutations, insertions, and deletions, have been reported in LIPA gene. Frameshift mutations are not frequently showed in WD.

Here, an 18-day-old female patient in whom the definite diagnosis was made by the LIPA gene sequencing is reported. Genetic analysis resulted in a novel frameshift mutation that has not been reported before.

Keywords: Wolman disease, LIPA gene, lysosomal acid lipase
\end{abstract}

\section{INTRODUCTION}

Wolman disease is observed in conditions wherein the lysosomal acid lipase (LAL) enzyme activity is less than $1 \%$ and is characterized by vomiting, diarrhea, poor weight gain, hepatosplenomegaly, and liver failure in the initial months of life (1). The LAL enzyme is the main enzyme responsible for the hydrolysis of cholesterol esters and triglycerides following the receptor-mediated endocytosis of low-density lipoprotein. Mutations in the LIPA gene on chromosome 10q23.2-q23.3 result in loss of LAL enzyme activity. Reduced enzyme activity leads to two separate clinical manifestations of autosomal recessive inheritance, namely Wolman disease and cholesterol ester depot disease (1). More than 40 mutations in the LIPA gene have been identified to date $(2$, 3). The storage of cholesterol esters and triglycerides in Wolman disease leads to progressive liver fibrosis, causing death in early infancy (4). The definitive diagnosis of Wolman disease is by measuring LAL enzyme activity in leukocytes or fibroblasts and by LIPA gene analysis $(2,5,6)$. The present study reports the case of a female patient who died due to liver failure, was diagnosed with Wolman disease on LIPA gene analysis, and had a mutation that had not been previously reported in the literature.

\section{CASE PRESENTATION}

An 18-day-old girl presented with hepatosplenomegaly and transaminase elevation. She was born as the fifth child of parents with first-degree cousin marriage. It was learned that abdominal distention, vomiting, and poor weight gain were also reported on the 20th day of life in the first two children of the family. The first child had died at 3 months of age, with no further examinations being performed, and the second child had died at 48 days of age, with similar complaints and with post-mortem histopathological examination of the liver biopsy samples revealing significant hepatic steatosis and fibrosis.

On physical examination, the 18-day-old girl had mildly rough facial appearance and umbilical hernia with marked abdominal distention. The liver and spleen were palpable at 6 and $4 \mathrm{~cm}$, respectively, below the costal margin. Laboratory tests revealed low levels of high-density lipoprotein (HDL) $(7 \mathrm{mg} / \mathrm{dL}, \mathrm{N}: 40-60$ $\mathrm{mg} / \mathrm{dL}$ ) associated with an increase in plasma triglyceride (253 $\mathrm{mg} / \mathrm{dL}, \mathrm{N}: 30-100 \mathrm{mg} / \mathrm{dL}$ ) and total cholesterol $(188 \mathrm{mg} / \mathrm{dL}, \mathrm{N}$ : $<170 \mathrm{mg} / \mathrm{dL}$ ) levels. The low alpha fraction in plasma lipoprotein electrophoresis was remarkable. Transaminase levels in the patient were SGOT $125 \mathrm{U} / \mathrm{L}, \mathrm{SGPT} 42 \mathrm{U} / \mathrm{L}, \mathrm{GGT} 55 \mathrm{U} / \mathrm{L}$, ALP $418 \mathrm{U} / \mathrm{L}$, total bilirubin $5.2 \mathrm{mg} / \mathrm{dL}$, total protein $4.4 \mathrm{~g} / \mathrm{dL}$, and albumin $3 \mathrm{~g} /$ dL. Hematological examination and coagulation tests were normal. Blood amino acid analysis, tandem MS acyl-carnitine analysis, urine organic acid analysis, and ammonia and lactate levels were normal. Abdominal ultrasonography revealed an enlarged liver and spleen and calcification in both adrenal glands (Figure 1). Abdominal magnetic resonance imaging revealed calcifica-

ORCID IDs of the authors: M.Ş.C. 0000-0003-3315-5124; M.A. 0000-0003-2289-9777; T.Z. 0000-0002-7159-4008. 


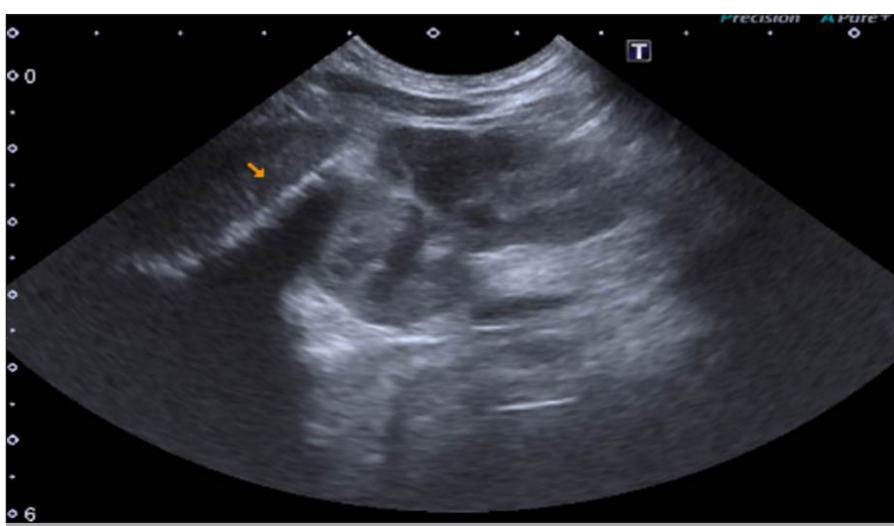

Figure 1. Abdominal ultrasound image of the patient revealing hepatosplenomegaly and bilateral adrenal calcification

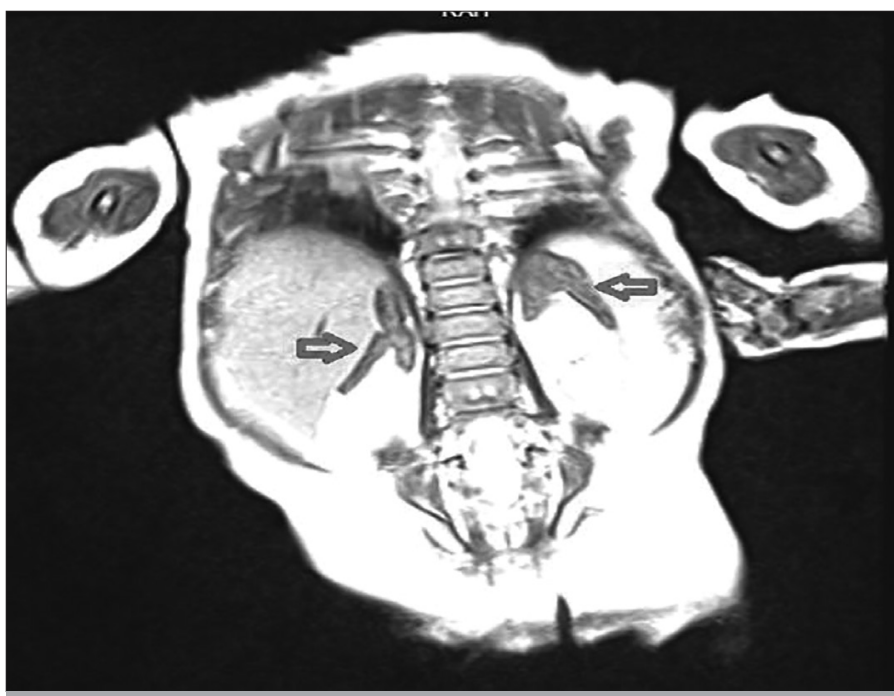

Figure 2. Abdominal magnetic resonance image of the patient revealing liver, spleen, and adrenal gland enlargement

tion and advanced expansion of the adrenal glands associated with an enlarged liver and spleen (Figure 2). In the dried blood sample test, the LAL enzyme activity was lower than $0.02 \mathrm{nmol} /$ punch/h (N: 0.37-2.30), and this result was suggestive of Wolman disease. A homozygous p.Q165Pfs*25 (c.493_494insC) mutation was detected on LIPA gene analysis. The mutation detected was a frameshift mutation, which had not been previously reported in the literature. Written informed consent was obtained from the patient's parents.

\section{DISCUSSION}

LAL enzyme deficiency is observed in two separate clinical manifestations, namely Wolman disease and cholesterol ester depot disease. Wolman disease is characterized by growth retardation, an enlarged liver and spleen, and liver failure in early infancy (1).

The LIPA gene encoding functional LAL enzyme activity is located in chromosome 10q23.2-q23.3, and currently, approximately 40 mutations that cause Wolman disease and cholesterol ester storage disease have been identified $(2,3,5)$. Patients affected with these diseases often have homozygous or compound het- erozygous mutations in their families (7-9). The most common mutation in cholesterol ester depot disease is identified in the region of the guanine adenine conversion point at the exon 8 junction. Mutations result in exon skipping, and the most common mutations have been reported to be E8SJM (c.894G>A; p.delS275_Q298; IVS8-1G>A ) mutations. This mutation has been termed E8SJM ${ }^{1 G>A}$ mutation in the recent literature. The E8SJM ${ }^{-1 G>A}$ mutation has been detected only in patients with cholesterol ester depot disease, and residual LAL enzyme activity continues to exist in the respective mutation. E8SJM ${ }^{+1 G>A}$ and $E_{8 S J M}{ }^{+3 C}>T$, which are exon 8 junction point mutations, have only been reported in patients with Wolman disease and result in complete loss of LAL enzyme activity (10). In our patient, molecular analysis of LIPA gene revealed a homozygous p.Q165Pfs*25 (c.493_494insC) mutation that had not been previously reported in the literature. This frameshift mutation is rare in Wolman disease.

Informed Consent: Written and verbal informed consent was obtained from parents of the patient who participated in this study.

Peer-review: Externally peer-reviewed.

Author Contributions: Concept - M.Ş.C., M.A., T.Z.; Design - M.Ş.C., M.A., T.Z.; Supervision - M.Ş.C., M.A., T.Z.; Resources - M.Ş.C., M.A.; Analysis and/or Interpretation - T.Z.; Literature Search - T.Z.; Writing Manuscript - M.Ş.C., T.Z.; Critical Review - T.Z.

Conflict of Interest: The authors have no conflict of interest to declare.

Financial Disclosure: The authors declared that this study has received no financial support.

\section{REFERENCES}

1. Assmann G, Seedorf U. Acid lipase deficiency: Wolman disease and cholesterol ester storage disease. The metabolic and molecular basis of inherited diseases. 2001 McGraw Hill Inc.: New York. p. 3551-72.

2. Stitziel NO, Fouchier SW, Sjouke B, Peloso GM, Moscoso AM, Auer $\mathrm{PL}$, et al. Exome sequencing and directed clinical phenotyping diagnose cholesterol ester storage disease presenting as autosomal recessive hypercholesterolemia. Arterioscler Thromb Vasc Biol 2013; 33: 2909-14.[CrossRef]

3. Gasche C, Aslanidis C, Kain R, Exner M, Helbich T, Dejaco C, et al. A novel variant of lysosomal acid lipase in cholesteryl ester storage disease associated with mild phenotype and improvement on lovastatin. J Hepatol 1997; 27: 744-50.[CrossRef]

4. Boldrini R, Devito R, Biselli R, Filocamo M, Bosman C. Wolman disease and cholesteryl ester storage disease diagnosed by histological and ultrastructural examination of intestinal and liver biopsy. Pathol Res Pract 2004; 200: 231-40.[CrossRef]

5. Aslanidis C, Ries S, Fehringer P, Buchler C, Klima H, Schmitz G. Genetic and biochemical evidence that CESD and Wolman disease are distinguished by residual lysosomal acid lipase activity. Genomics 1996; 33: 85-93.[CrossRef]

6. Hamilton J, Jones I, Srivastava R, Galloway P. A new method for the measurement of lysosomal acid lipase in dried blood spots using the inhibitor Lalistat 2. Clin Chim Acta 2012; 413: 1207-10.[CrossRef]

7. Ries S, Aslanidis C, Fehringer P, Carel JC, Gendrel D, Schmitz G. A new mutation in the gene for lysosomal acid lipase leads to Wolman disease in an African kindred. J Lipid Res 1996; 37: 1761-5.

8. Fujiyama J, Sakuraba H, Kuriyama M, Fujita T, Nagata K, Nakagawa $\mathrm{H}$, et al. A new mutation (LIPA Tyr22X) of lysosomal acid lipase gene 
in a Japanese patient with Wolman disease. Hum Mutat 1996; 8: 377 80.[CrossRef]

9. Mayatepek E, Seedorf U, Wiebusch H, Lenhartz H, Assmann G. Fatal genetic defect causing Wolman disease. J Inherit Metab Dis 1999; 22: 93-4.[CrossRef]
10. Ameis D, Brockmann G, Knoblich R, Merkel M, Ostlund RE Jr, Yang JW, et al. A 5' splice-region mutation and a dinucleotide deletion in the lysosomal acid lipase gene in two patients with cholesteryl ester storage disease. J Lipid Res 1995; 36: 241-50. 